\title{
Investigation of influence of tool rake angle in single point diamond turning of silicon
}

\author{
Amir Mir ${ }^{1} \cdot$ Xichun $\mathrm{Luo}^{1} \cdot$ Kai Cheng ${ }^{2} \cdot$ Andrew Cox $^{3}$
}

Received: 21 May 2017 / Accepted: 22 August 2017 / Published online: 8 September 2017

(C) The Author(s) 2017. This article is an open access publication

\begin{abstract}
This paper presents an investigation of the effect of tool rake angle in single point diamond turning (SPDT) of silicon using experimental and simulation methods. Machining trials under the same cutting conditions were carried out using three different rake angle tools. In order to delve further into the rake angle effect on the output parameters including material removal, stresses and crack formation, at the onset of chip formation and steady-state conditions, a simulation study using smoothed particle hydrodynamics (SPH) approach was performed. The simulation results were incorporated and found in good agreement with experimental observations. The results indicate that diamond tool wear rate and surface generation mechanism significantly vary using different rake angle tools. The continuance of compressive and shear deformation sequence at the chip incipient stage governs the high-pressure phase transformation (HPPT) as a function of rake angle and tool wear. The capability of diamond tool to maintain this sequence and required hydrostatic pressure under worn conditions is highly influenced by a change in rake angle. The proportional relationship of cutting force magnitude and tool wear also differs owing to disparate wear pattern which influence distribution of stresses and uniform hydrostatic pressure under the tool cutting edge. This subsequently influences structural phase transformation and
\end{abstract}

Xichun Luo

xichun.luo@strath.ac.uk

1 Centre for Precision Manufacturing, Department of Design, Manufacture and Engineering Management, University of Strathclyde, Glasgow, UK

2 Department of Mechanical, Aerospace and Civil Engineering, Brunel University, London, UK

3 Contour Fine Tooling Ltd., Stevenage, Herts, UK therefore frictional resistance to cutting. Mainly frictional groove wear was found dominant for all diamond tools in machining of silicon.

Keywords Diamond turning · Silicon · Tool geometry · Tool wear · Chip formation

\section{Introduction}

Single crystal silicon is considered an ideal material in microphotonics and weight-sensitive infrared applications due to its low mass density, high refractive index and low thermal expansion coefficient. High form precision and submicrometer surface finish are the key requirements of silicon-based functional surfaces for these applications. Single point diamond turning (SPDT) is an effective ultra-precision machining method to fabricate products with high form accuracy and optical surface finish without the need for subsequent polishing. SPDT of silicon is inherently a complex process that includes chipping, brittle fracture, ductile deformation, chemical reaction and phase transformation as a function of cutting parameters, material orientation and tool geometry. The rapid wear of diamond tool is also a critical aspect that influences the surface integrity and operational cost of SPDT and need to be in limit and controlled.

A comprehensive understanding of coherence of silicon machining mode and tool geometry is imperative to achieve cost-effective and efficient SPDT by realising prolonged ductile mode machining at reduced tooling cost. The major reported work in the past reveal the significance of highpressure phase transformation (HPPT) as a function of tool geometry which facilitates plastic deformation of silicon and accordingly influence tool wear mechanism [1-3]. The change in material properties of silicon as a function of 
HPPT significantly affects frictional resistance, chip formation and chemical affinity consequently influencing tool wear during machining. Hence, there exists an interdependency of tool geometry and machining mechanism of silicon which affects machining performance.

The previous studies reveal that by careful selection of cutting parameters and tool geometry, ductile mode machining of silicon exploiting HPPT can be achieved [4-6]. From the tool geometry perspective, negative rake angle tools were found to generate high hydrostatic pressure required for structural transformation of silicon ensuing brittle to ductile transition (BDT). The increase of critical chip thickness was also claimed to increase with an increase in negative rake angle of the tool. Blake and Scattergood [5] performed SPDT of silicon and germanium using diamond tools with rake angles of $0^{\circ}$, $-10^{\circ}$ and $-30^{\circ}$. They observed an increase of critical chip thickness from $0^{\circ}$ to $-10^{\circ}$ rake and found a sharp increase in critical chip thickness at $-30^{\circ}$ rake. Yan et al. [7] observed an increase of critical chip thickness from $0^{\circ}$ to $-40^{\circ}$ rake angle tools. Shibata et al. [8] conducted machining of silicon using $-20^{\circ}$ and $-40^{\circ}$ rake diamond tools at $100 \mathrm{~nm}$ and $1 \mu \mathrm{m}$ depth of cut. They found that rake angle effect diminishes at a depth of cut of $100 \mathrm{~nm}$ and becomes prominent from $100 \mathrm{~nm}$ to $1 \mu \mathrm{m}$ in all crystallographic orientations. Zang et al. [9] suggested the importance of effective rake angle in association with cutting edge radius and depth of cut. Using $0^{\circ}$ rake angle and $-25^{\circ}$ rake angle tools, they observed surface deterioration for an effective rake angle of $\sim-60^{\circ}$ rake using $-25^{\circ}$ tool and surface finish of $1 \mathrm{~nm}$ using lower negative effective rake angle. Diamond tools with negative rake angle are also assumed to provide cutting edge strength against any chipping or abrasive damage and consequently more control on an abrupt tool wear. Cutting edge sharpness of diamond tools considerably affect surface roughness and, therefore, considered also to be an important factor in achieving the optical surface quality of silicon.

Although negative rake angle is commonly agreed to be very important in achieving BDT of silicon, a clear disagreement pertaining to rake angles for ductile mode machining is found in the literature. In SPDT of silicon, diamond tools with intermediate negative rake angle from $-20^{\circ}$ to $-50^{\circ}$ are considered ideal for ductile mode machining. Positive rake angle tools are considered inefficient to produce required hydrostatic pressure for HPPT of silicon whereas negative rake angles greater than $-50^{\circ}$ are considered to cause obstruction in material removal. Although ductile mode machining of silicon has been realised using neutral $0^{\circ}$ rake angle tools [10-12], intermediate rake angle, as well as extreme negative rake angles of $-80^{\circ}$ and $-85^{\circ}[5,8,13]$, maintaining ductile mode machining for longer cutting distance has not been considered in these studies. Also, a key factor to consider is the capability of worn tools of different rake angle tools to maintain HPPT for longer ductile mode machining. Therefore, there is a need to recognise an optimal rake angle that could maintain HPPT-based longer ductile mode machining and at the same time offer reduced tool wear.

In this paper, smoothed particle hydrodynamics (SPH)based numerical simulation study using Drucker-Prager (DP) material constitutive model was conducted in conjunction with machining experiments to investigate the effect of different rake angle tools. SPH method has been successfully employed in the machining of various ductile materials [14-16]. However, simulations of machining of brittle materials using SPH method are very few. Silicon is one of the hardest and brittle materials never been simulated (in the author's knowledge) for cutting process using SPH. The simulation model of silicon using SPH method and constitutive DP model was proposed in this study to better predict the pressure-dependent plastic behaviour and crack formation of the material.

The first section of the paper describes the SPH formulation and its appropriateness for the machining model in comparison with Lagrangian mesh-based approach. A brief introduction of DP model was provided in the next section. The experimental plan and numerical simulation model of SPDT using SPH approach were presented in the following sections. The experimental and numerical simulation results were then evaluated by analysing the cutting force magnitude and trend, chip formation, surface finish and tool wear.

\section{Smoothed particle hydrodynamics formulation}

The SPH approach was first developed by Gingold and Monaghan in 1977 [17] for astrophysics applications. SPH uses kernel approximation to approximate field variables and properties in the domain as shown in Fig. 1. SPH approximate field variables at any particle by classical summation of smoothing function values of neighbouring particles within a sphere of influence. The length that defines the sphere of

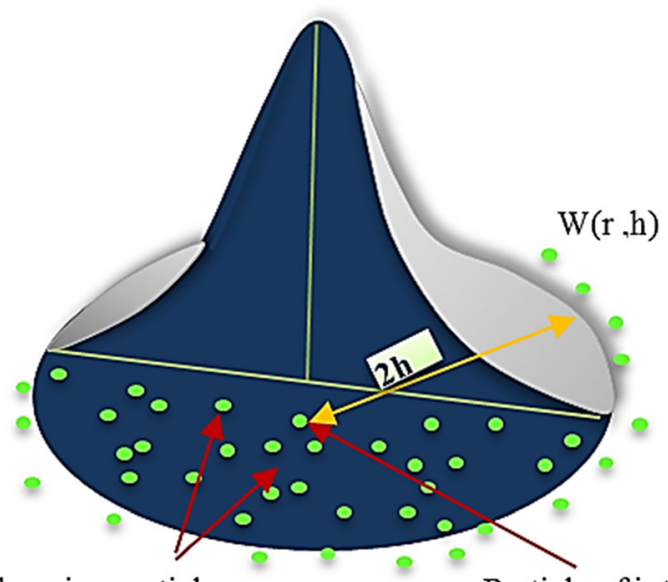

Neighbouring particle

Particle of interest

Fig. 1 SPH kernel approximation 
Fig. 2 Drucker-Prager model. (a) Mohr-coulomb and DP model in deviatoric plane. (b) DP yield surface

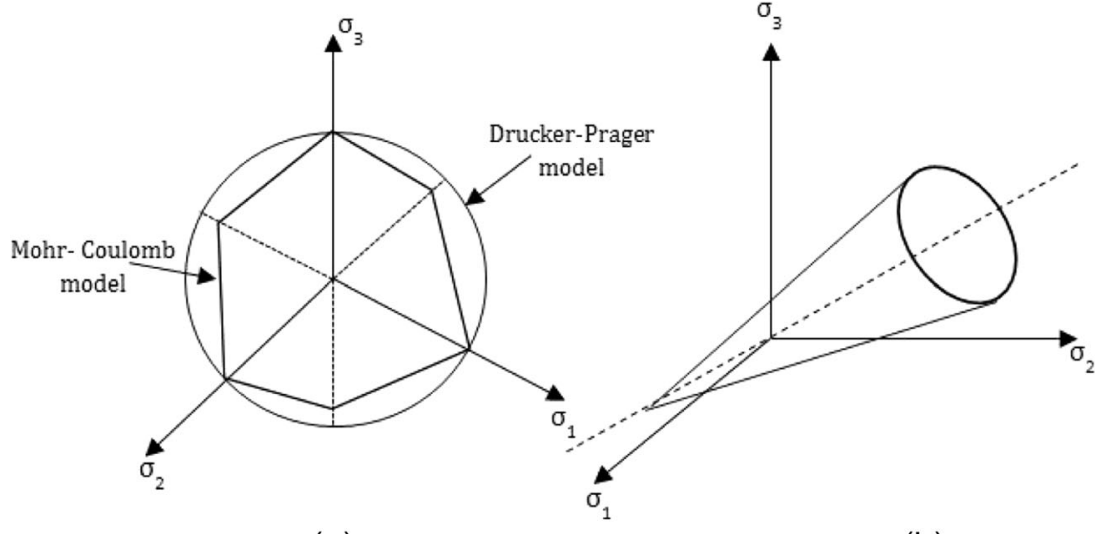

(a) (b) influence is based on smoothing length, and it is the maximum distance to which the interaction can occur:

$\mathrm{f}(\mathrm{x}) \cong \sum_{\mathrm{j}}^{\infty} \frac{\left(\mathrm{m}_{\mathrm{b}}\right)}{\rho_{\mathrm{b}}} \mathrm{f}_{\mathrm{b}} \mathrm{W}\left(\left|\mathrm{X}-\mathrm{X}_{\mathrm{b}}\right|, \mathrm{h}\right)$

where $f(x)$ is a scalar function and subscript $b$ represents the neighbouring particle of the particle $a$ for which field variables need to be approximated. $W$ is a smoothing Kernel function with radius $h$, called smoothing length. $m_{b}$ and $\rho_{b}$ are mass and densities of $b$ particles. $X_{b}$ is location of particle $b$ with its value $f_{b}$.

Although Lagrangian mesh-based approach has been well researched in the FE simulations of machining of ductile materials [18, 19], simulation of hard and brittle materials such as silicon and silicon carbide using this approach is difficult and becomes impractical when using higher negative rake angle tools. This is not only because the pressuredependent machining mechanism varies as a function of tool geometry and machining conditions; but also, the true critical parameter values of physical and geometrical criteria for crack formation [20-22] along with pressure-dependent brittle damage models are difficult to be identified. Also, due to the negative rake angle of the tools, implementation of crack formation criteria along a dedicated layer becomes impractical. Due to the mesh-less nature and suitable particle connectivity, SPH offers continuous and discontinuous material removal due to plastic deformation and brittle fracture respectively without any separation criteria. The method presents a profound insight of variations in natural chip formation, hydrostatic pressure and stress distribution in brittle materials as a function of tool geometry and therefore carries great significance. In comparison to the mesh-based Lagrangian formulation, SPH approach was found less efficient in studying processes with tensile instability or in small deformation processes [23]. Nevertheless, it has been found more expedient to study large deformation processes (as in cutting processes) than Lagrangian mesh-based approach. SPH approach has also been found to perform in an analogous manner to mesh-based approach following sensitivity analysis of particle resolution, mass-scaling and better in interface friction criteria [24].

In SPH method, all particles have a physical degree of freedom and each particle movement is influenced by its neighbouring particles located within the sphere of influence of radius $r$ which is twice the smoothing length, $2 \mathrm{~h}$. The particles beyond the area of influence do not contribute to the intrinsic property of cohesion on the particle of interest. In SPH formulation, particles interact with each other based on defined constitutive equations and friction criteria is based on the internal friction between the particles instead of using theoretical friction parameters.
Fig. 3 Machining setup of SPDT of silicon and SEM image of the new tool
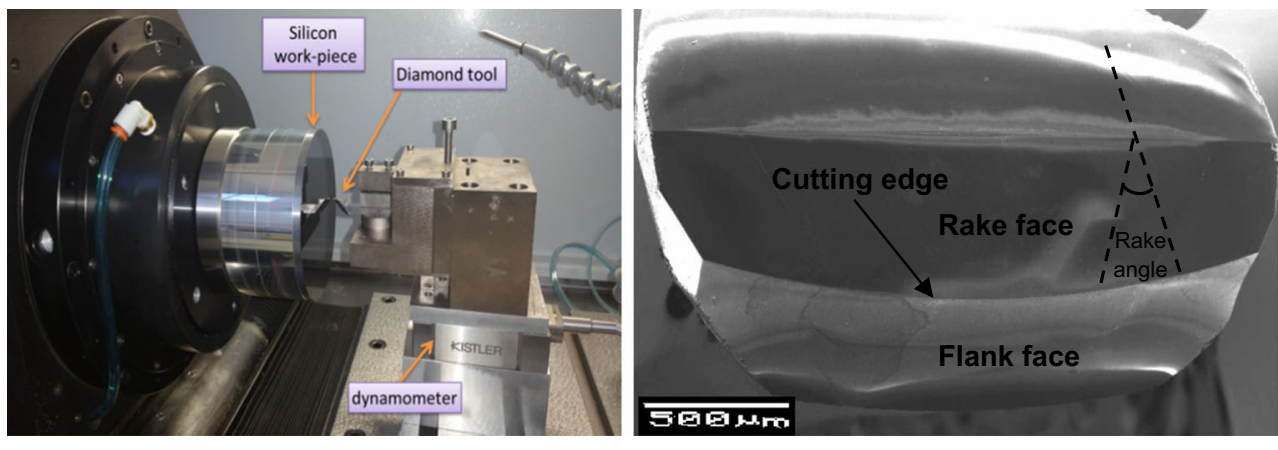
Table 1 Experimental machining data and conditions

\begin{tabular}{lll}
\hline Silicon wafer & Diamond tools & Cutting parameters \\
\hline Optical grade silicon, polished & Orientation $=$ dodecahedral & Spindle speed $=1200 \mathrm{rpm}$ \\
Round & Nose radius $=5 \mathrm{~mm}$ & Feed rate $=1 \mu \mathrm{m} / \mathrm{rev}$ \\
Orientation $=<111> \pm 5^{\circ}$ & Rake $/$ clearance angle: & Cutting speed $=3-6.2 \mathrm{~m} / \mathrm{s}$ \\
Diameter $=100 \mathrm{~mm}$ & Tool1 $=-25^{\circ} / 10^{\circ}$ & Depth of cut $=10 \mu \mathrm{m}$ \\
Thickness $=5 \mathrm{~mm}$ & Tool $2=-30^{\circ} / 10^{\circ}$ & Coolant $=$ distilled water \\
Sample purity $=99.999 \%$ & Tool $3=-40^{\circ} / 25^{\circ}$ & \\
\hline
\end{tabular}

\section{Drucker-Prager model}

Drucker-Prager (DP) plasticity model has widely been implemented to simulate deformation behaviour of pressuredependent materials including concrete and rocks. In pressure-dependent materials, a general trend is an increase in material strength with increasing confining pressure. Silicon behaves as a ductile material under specific higher hydrostatic stress zones. The strength of the silicon increases and the material deforms plastically under loading conditions.

In the von Mises yield criterion, the second deviatoric stress tensor $J_{2}$ is regarded solely as material yielding criteria without considering first stress invariant $I_{1}$. When considering pressure-dependent materials, the yielding sensitivity to hydrostatic stress tensor has not been taken into consideration in this criterion. In 1952, Drucker and Prager [25] developed yield criteria and incorporated the effect of hydrostatic stress for pressure-sensitive materials. This pressure-dependent model is known as Drucker-Prager model (also regarded as modified Mohr-Coulomb's model or extended von Mises model). Figure 2 presents the DP yield surface which is the function of pressure and $J_{2}$ along with the Mohr-Coulomb model. The yield criterion of DP model is described as

$\mathrm{f}\left(\mathrm{I}_{1}, \mathrm{~J}_{2}\right)=\alpha \mathrm{I}_{1}+\sqrt{\mathrm{J}_{2}}-\mathrm{d}=0$

In Eq. (2), $I_{1}$ and $J_{2}$ are the first and second stress invariants, $d$ is material cohesion and $\alpha$ is the hydrostatic-pressure sensitivity coefficient. The linear DP model can be represented by three invariants of stress tensor [26] and described as

$\mathrm{f}=\mathrm{t}-p \tan \beta-d=0$

where $t$ and $P$ are the deviatoric effective stress and equivalent pressure stress respectively and $\tan \beta$ represents the hydrostatic pressure-dependent yielding sensitivity of material. The parameter $\beta$ is known as friction angle which represents the slope of the linear yield surface in meridional $\mathrm{p}$-t stress plane.

\section{Experimental plan}

The SPDT of silicon with high surface quality and minimal sub-surface damage is only possible with stiff machine tools.
In this research, machining trials were carried out on an ultraprecision diamond turning machine-Nanotech 250 UPL (Moore Nanotech system) which is equipped with airbearing spindle offering low friction and less heat generation and hydraulic motional slides of high stiffness.

Single crystal diamond tools in dodecahedral crystal orientation were used to machine P-type silicon wafers of (111) crystal orientation. Figure 3 shows the machining setup and SEM image of negative rake round edge tool used in SPDT of silicon. Three different negative rake angle tools were used in order to investigate the effect of rake angle on surface generation mechanism of silicon.

Cutting edges as well as rake and flank faces of new diamond tools were carefully examined under SEM for any prior damage. The selection of cutting parameters and coolant was based on previous established research work of diamond turning of silicon to attain high optical quality machining [27]. Large nose radius tools were used as they provide strong edge geometry to withstand higher frictional resistance and higher cutting forces. Critical depth of cut as well as critical feed rate for brittle to ductile transition were also found to increase with increasing nose radius during SPDT of brittle materials [28, 29]. Table 1 presents tools and workpiece details and machining conditions adopted in the experimental work.

Each silicon wafer was divided into two zones: facing and plunge zones. The facing cuts were performed repeatedly with the same $10 \mu \mathrm{m}$ depth of cut and $1 \mu \mathrm{m} / \mathrm{rev}$ cross-feed until the onset of the brittle fracture. In the reiteration of facing cut, the

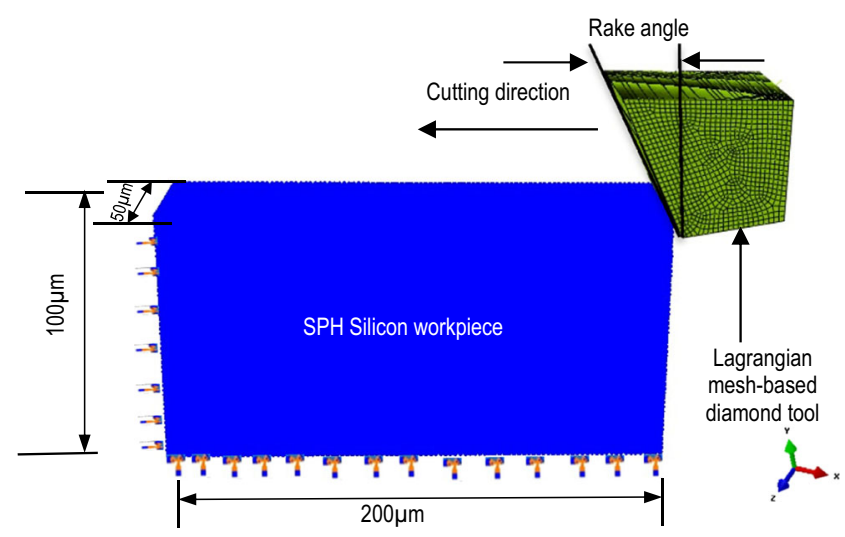

Fig. 4 SPH cutting simulation model of silicon 
Table 2 Cutting parameters used in SPH simulation

\begin{tabular}{|c|c|c|c|c|}
\hline & Rake/clearance angle & Workpiece size $(\mu \mathrm{m})$ & Cutting speed $(\mathrm{m} / \mathrm{s})$ & Depth of cut $(\mu \mathrm{m})$ \\
\hline 1 & $+5^{\circ} / 10^{\circ}$ & \multirow[t]{4}{*}{$200 \times 100 \times 50$} & \multirow[t]{4}{*}{6.3} & \multirow[t]{4}{*}{10} \\
\hline 2 & $-25^{\circ} / 10^{\circ}$ & & & \\
\hline 3 & $-30^{\circ} / 10^{\circ}$ & & & \\
\hline 4 & $-40^{\circ} / 10^{\circ}$ & & & \\
\hline
\end{tabular}

tool retraction radius for each following facing cut was reduced by $1 \mathrm{~mm}$.

Cutting forces were monitored and recorded using a threecomponent Kistler dynamometer 9256. An advanced data acquisition system with Dynoware software was used to get the Fx, Fy and Fz forces. Surface roughness was measured using a white light interferometry (Zygo Newview 5000) for each iteration of facing cuts. The tools were monitored after machining under SEM for any induced wear or damage caused by the machining trials. The cutting distance was calculated for each diamond tool before the onset of brittle fracture to measure tool performance.

Confirmation trials were also performed using the same tool and workpiece geometries, orientations and machining conditions. The methodology for monitoring tool conditions, cutting forces and surface finish were the same adopted in the first trial.

\section{$5 \mathrm{SPH}$ cutting simulation model}

In machining operations, concurrently occurring phenomena including material removal, HPPT, stresses as well as crack nucleation and propagation, at the onset of chip formation occur in an infinitesimal fraction of time and scale. It is nontrivial to understand these output variable state and conditions as it significantly influences tool geometry performance as well as tool wear. However, it is difficult to measure and observe these output variables in experimental conditions. In this research, SPH-based simulations of orthogonal cutting of silicon were carried out using finite element (FE) software Abaqus to study these output variables.

In order to corroborate the rake angle effect observed during the experimental study, SPH simulations of SPDT of silicon were performed under the same cutting conditions using different rake angle tools. The tool was modelled with eight-noded C3D8R elements using Lagrangian element-based mesh and

Table 3 Material properties of silicon

\begin{tabular}{ll}
\hline Density, $\rho$ & $2330 \mathrm{~kg} / \mathrm{m}^{3}$ \\
\hline Elastic modulus, E & $146 \mathrm{GPa}$ \\
Poison's ratio & 0.27 \\
Friction angle $(\beta)$ & $26^{\circ}$ \\
Dilation angle $(\Psi)$ & $20^{\circ}$ \\
Flow stress ratio, $\mathrm{k}$ & 0.82 \\
\hline
\end{tabular}

was kept rigid due to significantly high modulus of diamond compared to silicon. The workpiece was modelled as a deformable part with PC3D particles to handle large deformation during the cutting process. The workpiece dimensions were kept at $(200 \times 100 \times 50) \mu \mathrm{m}$. The bottom of the workpiece was retained in all directions. In cutting simulation, the tool moves with similar experimental cutting velocity in the negative $\mathrm{x}$-direction. Figure 4 shows a cutting simulation model used in this study.

In order to examine the rake angle effect, cutting simulations were performed with four different rake angle tools using the same cutting conditions adopted in experiments. Although diamond tool with $+5^{\circ}$ rake angle was not used during the experimental trials, it was included in the simulation study to provide the comparison of chip formation and distribution of different stresses using positive and negative rake angle tools. Table 2 shows the cutting parameters used in the simulation study.

The Drucker-Prager (DP) constitutive material model was adopted in this study to simulate the machining behaviour of silicon. The compressive yield strength of silicon is higher compared to its tensile strength [30] which is an elementary criterion of using DP model. Table 3 lists the material properties and DP model parameters of silicon [31] used in SPH cutting simulation.

\section{Results and discussions}

SPDT of silicon using three different rake angle tools was carried out until the onset of brittle fracture. Figure 5 shows the diamond-turned silicon wafer with severe brittle fracture that appeared in a threefold symmetry pattern. Due to the high anisotropy of single crystal silicon, machining mode is dependent on crystallographic orientation based on the orientation of dislocation and slip system relative to cutting direction.

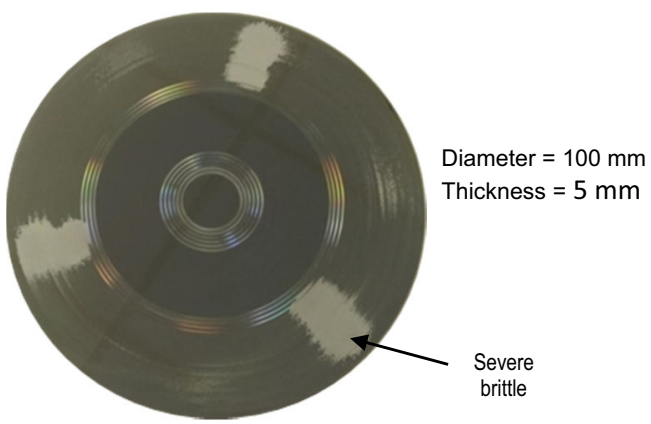

Fig. 5 Brittle fracture in threefold pattern on silicon 
Fig. 6 Thrust forces trend with cutting distance

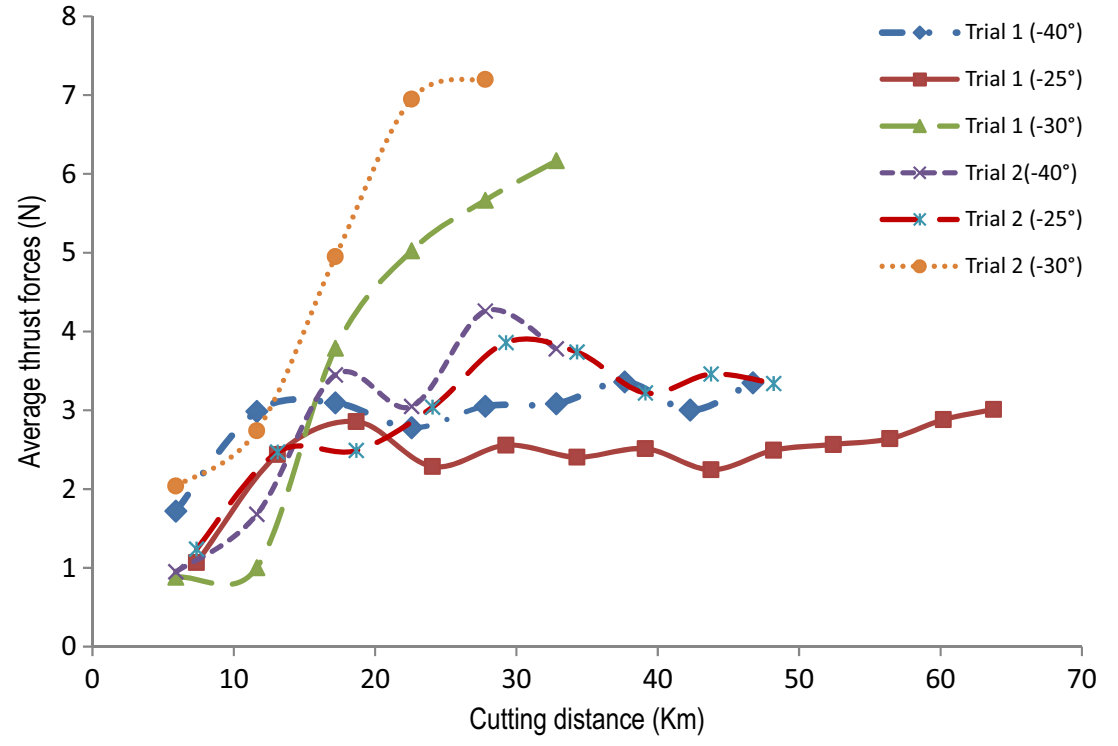

Therefore, in face turning of silicon with (111) orientation, the threefold pattern of cloudy surface has been reported frequently $[28,32]$.

The results of output parameters obtained using different rake angle tools were recorded and discussed in the following sections. Tool rake angle is considered as a determining factor of surface generation mechanism in SPDT of silicon. In order to investigate the rake angle effect, cutting forces, stresses, hydrostatic pressure, chip formation and tool wear were measured and analysed for different rake angles.

\subsection{Cutting forces}

Cutting forces are considered as the most accredited indicator to characterise material removal modes, frictional resistance to cutting, as well as tool wear. Cutting forces were recorded in each facing cut for all rake angle tools. Although cutting temperature has a significant effect on cutting force magnitude as high cutting temperature during machining results in softening of the material as well as change of machining mode, cutting temperatures during SPDT of silicon were not recorded high enough $[33,34]$ to cause any softening of material and therefore should not affect the cutting force magnitude significantly.

Figure 6 presents average thrust forces recorded in trial 1 and trial 2 with respect to cutting distance for different rake angle tools. In both the trials, diamond tools with $-25^{\circ}$ rake angle attained the longest cutting distance before the onset of brittle fracture followed by $-40^{\circ}$ rake tools. With the increasing cutting distance, tool wear develops which results in an increase of cutting forces. Cutting force trend suggests the maximum tool wear rate from 0 to $20 \mathrm{~km}$ and then gradual frictional wear for the rest of the cutting distance. This phenomenon substantiates the understanding of higher wear rate of sharp edges of new tools due to stress concentration in the cutting-edge zone. For $-30^{\circ}$ rake angle, the tool achieved the least cutting distance with the sharp rise of cutting forces. Similar cutting force behaviour of the $-30^{\circ}$ rake tool was recorded during the confirmation trials.

Figure 7 presents the tangential to thrust force ratio for the three different rake angle tools. Although for the $-30^{\circ}$ rake tool, the thrust forces were found higher than tangential forces, and the relative magnitude of the tangential force is higher than the other two tools. This explains the dominant cutting phenomenon with reduced compressive stresses and hence early brittle fracture.

Machining forces were measured in SPH cutting simulation of silicon using different rake angle tools. Figure 8 presents a comparison of experimental and simulation-based mean thrust forces. A good correlation of forces can be seen for the $-25^{\circ}$ and $-40^{\circ}$ rake angle tools except the $-30^{\circ}$ rake tool for which the percentage difference increased to $30 \%$ between experimental and simulation values. This high difference could possibly be due to the resulting cutting force vector coincide or close enough to the preferred direction of silicon crystal structure in the (111) direction and require further investigation.

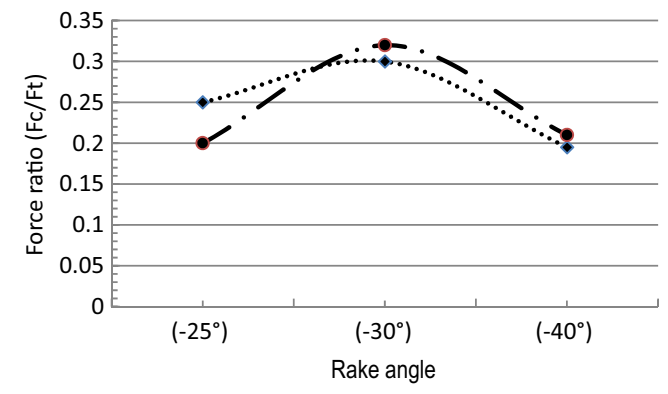

Fig. 7 Force ratio trend with decreasing rake angle 


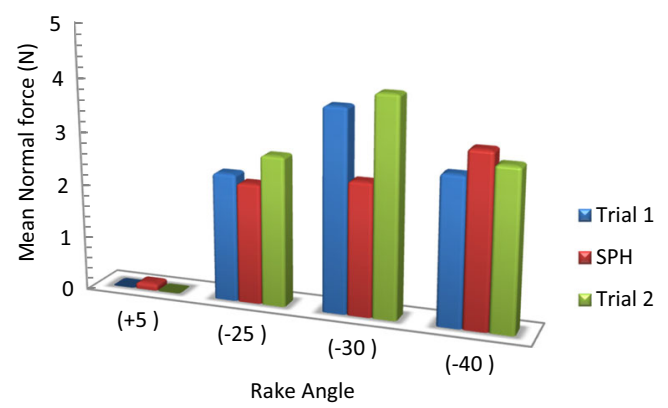

Fig. 8 Comparison of experimental and simulation cutting forces

\subsection{Stress distribution and chip formation}

The mechanics of chip formation during machining can be better understood by understanding the deformation conditions in the chip formation zones. Any change in tool geometry significantly influences shear stresses, strain and temperature distribution during chip formation. Figure 9 presents the schematic of cutting process in SPDT process.

The geometry of the primary shear zone (PSZ) is governed by the shear plane angle $\left(\varnothing_{\mathrm{s}}\right)$ and the ratio of the length of PSZ $\left(\mathrm{L}_{\mathrm{AB}}\right)$ to its thickness $\left(\mathrm{t}_{\mathrm{p}}\right)$. Figure 10 presents the change of shear plane length and shear angle with the change of rake angle. With the increase of shear zone area, the strength of the material increases and hence increases in deformation energy. It can be noted that shear angle reduces with the increase in negative rake angle from $-25^{\circ}$ to $-40^{\circ}$. Although shear plane area and shear strain magnitude increase with increasing negative rake angle tool, the length of PSZ decrease from $-25^{\circ}$ to $-30^{\circ}$ and then increases for $-40^{\circ}$ tool.

Stresses and pressure distribution and chip formations were also investigated in cutting simulation with different rake angle tools. Von Mises stresses were found to increase beyond the theoretical yield strength of silicon for all negative rake angle tools and continuous material removal observed throughout the cut. For the $+5^{\circ}$ rake angle tool, although, at first contact, the maximum von Mises stress reached $10 \mathrm{GPa}$ at tool-chip interface in the primary deformation zone, initiated by a crack in front of material separation tool tip propagating in the forward direction. Figure 11 shows the crack formation and surface damage on the removal of chip segment using positive rake tool.

Bending stresses develop at the bottom surface of the chip, and broken chips can be observed from the initiation to the concluding stage of chip separation. An average hydrostatic static pressure of $4 \mathrm{GPa}$ was recorded for $+5^{\circ}$ tool compared to negative rake angle tools. The average hydrostatic pressure of 15,14 and $19 \mathrm{GPa}$ was recorded for $-25^{\circ},-30^{\circ}$ and $-40^{\circ}$ tool respectively. Due to the lack of required hydrostatic pressure under the tool tip for $+5^{\circ}$ tool, chip separation occurs due to developed cracks and result in discontinuous material removal. On the removal of chip segment, surface ahead of the tool undergoes pitting damage under the cutting depth. The direction of developed crack also defines the final machined surface as any crack propagation angle towards the final machined surface result into brittle damage.

Figure 12 shows the von Mises stresses and the variation of chip formation for different negative rake angle tools. An imperative aspect to notice was the variation of stresses with an increase in negative rake angle. In general, an increase in stresses is likely to be predicted with an increase of negative rake angle. Nevertheless, at contact stage, von Mises stresses were found higher for the $-25^{\circ}$ rake than the $-30^{\circ}$ and $-40^{\circ}$ rake tools. Since lower negative rake tools are likely to initiate chip formation along with compressive stress at first contact with the workpiece surface, shear stresses remain dominant than compressive stresses. With the increasing negative rake, compressive stresses surpass shear stresses at initial contact with the workpiece surface.

At steady-state conditions, developed stresses for the $-40^{\circ}$ rake tool significantly increased than other two tools. This phenomenon attributed to the increase of yield strength of silicon with increasing hydrostatic stress using higher negative rake angle tools. However, for $-30^{\circ}$ rake angle, von Mises stresses at initial and steady-state conditions were found lower than the $-25^{\circ}$ rake tool. This behaviour validates the
Fig. 9 Schematic of chip formation in SPDT

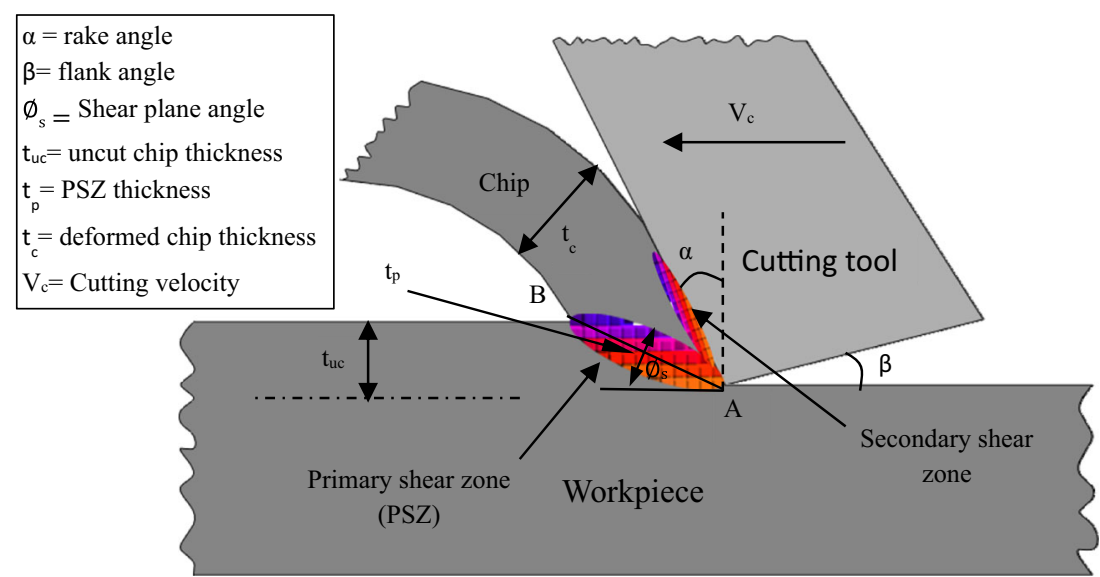




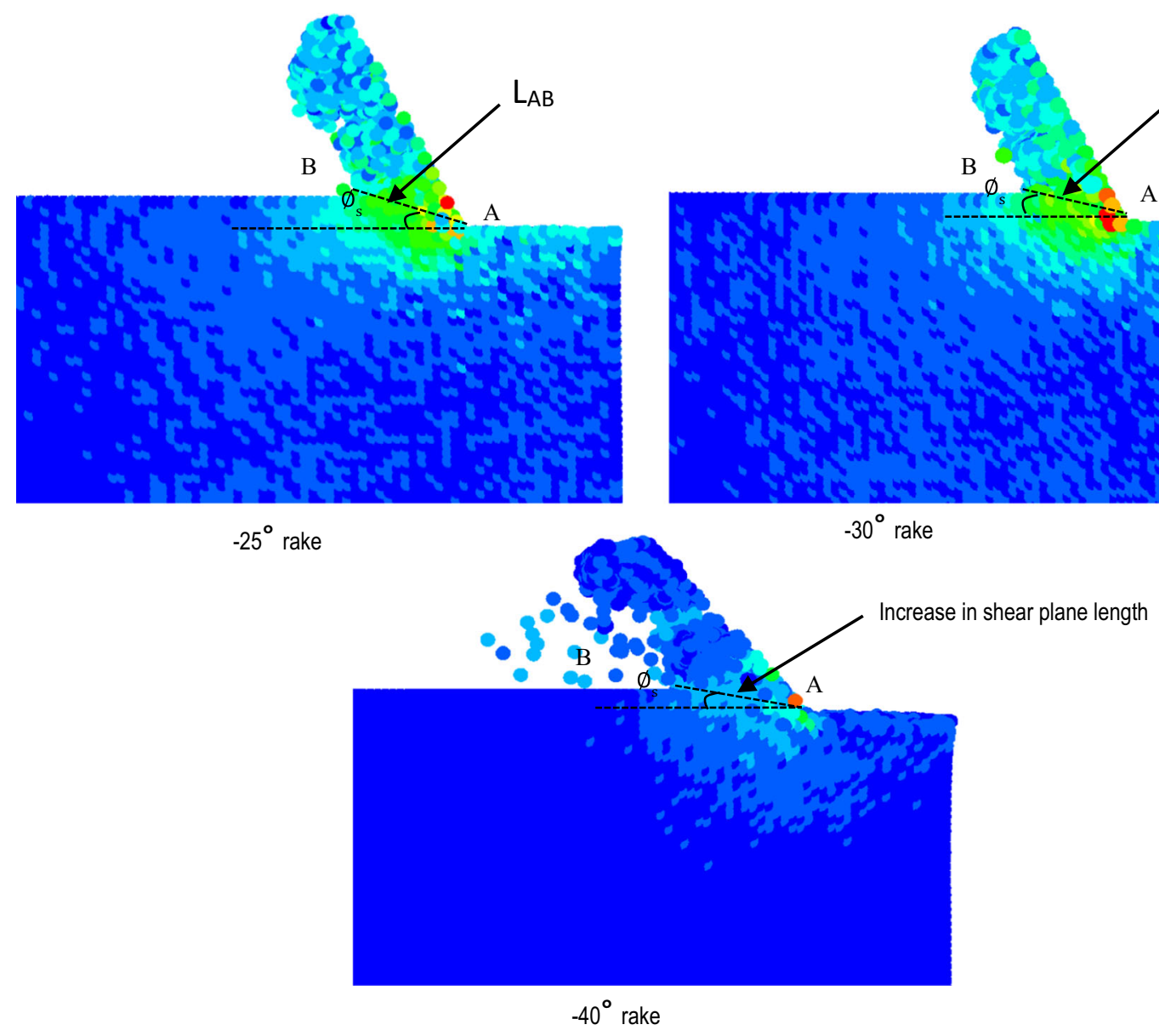

Fig. 10 Change of shear plane length and shear angle

shortening of shear plane length using the $-30^{\circ}$ tool in Fig. 10 which results in a decrease of von Mises stresses. The failure stresses can also be influenced by the intensity and sequence of compressive and shear stress from incipient to steady-state condition as a function of rake angle. Also, the type of chip formation ahead of the tool contributes to the normal and shear stress distribution on the tool rake face and cutting edge.

In SPDT of silicon, chip contour in secondary deformation zone (SDZ) also influence by the unloading conditions. In machining, the unloading mainly transpires at machined

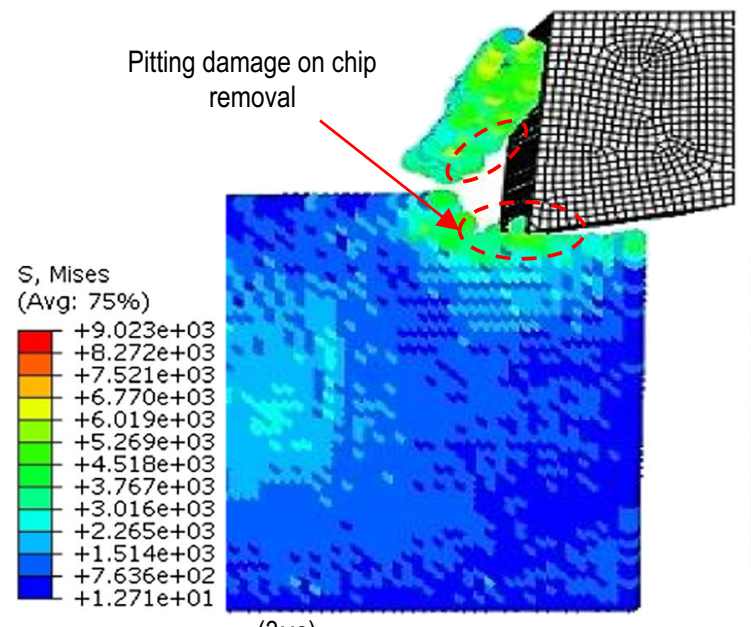

$(3 \mu \mathrm{s})$

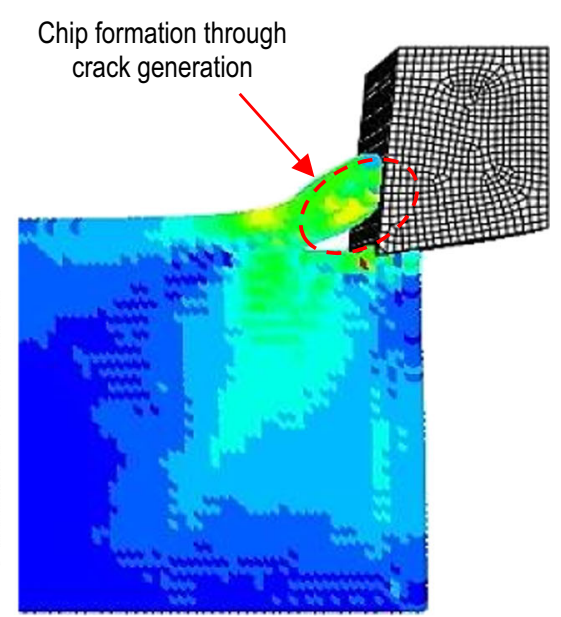

$(1.5 \mu \mathrm{s})$

Fig. 11 Chip formation using $+5^{\circ}$ rake angle 
surface behind the tool edge as well as reduce loading condition develop at tool-chip interface in SDZ. This change affects machined surface and chip contour in SDZ which can be observed in Fig. 12. For the $-25^{\circ}$ tool, the chip breaks into segments and particles in SDZ. The severity of the disintegration into particle was observed higher for $-40^{\circ}$ compared to $-25^{\circ}$ tool indicating high unloading effect. For $-30^{\circ}$ tool, the chip remained continuous without breakage. In order to further investigate this behaviour, pressure distribution study was performed.

\subsection{Chip geometry}

A good correlation of chip formation was found in experimental and SPH machining studies of silicon. Figure 13 shows the SEM images of silicon chips collected in the first facing cuts for the three rake angle tools. Chips were formed in the combination of continuous, broken and powder forms with different thickness. For $-25^{\circ}$ rake angle tool, chips were mainly formed in combination of continuous and broken chips along with dominant powder form. Smoother and longer ribbon type chips were observed using $-30^{\circ}$ rake angle tool. Similar behaviour can be observed in $\mathrm{SPH}$ simulations where for $-30^{\circ}$ tool, chips remain continuous in the SDZ. On the other hand for $-25^{\circ}$ and $-40^{\circ}$, chips were found to break into particles due to unloading effect.

For both $-25^{\circ}$ and $-40^{\circ}$ tools, although the chips were found in the combination of ribbon, broken and powder form, the chip shapes were observed distorted using $-40^{\circ}$ tool. The distortion could possibly be due to the flow of chip under the tool with high compressive stresses.

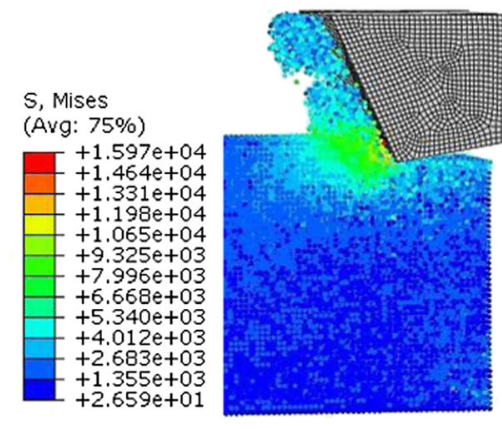

$-25^{\circ}$ rake $(6 \mu \mathrm{s})$

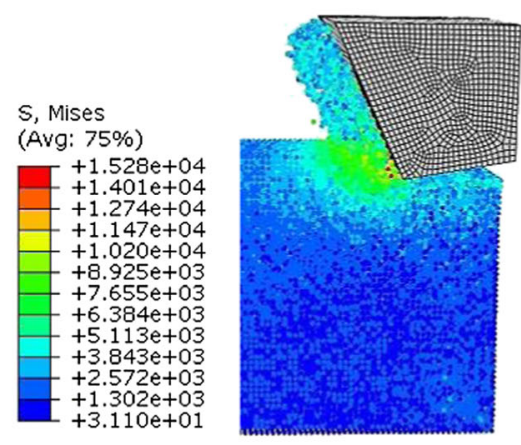

$-30^{\circ}$ rake $(6 \mu \mathrm{s})$

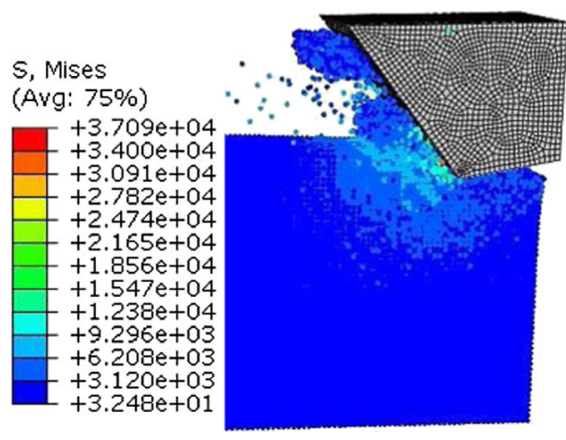

$-40^{\circ}$ rake $(6 \mu \mathrm{s})$

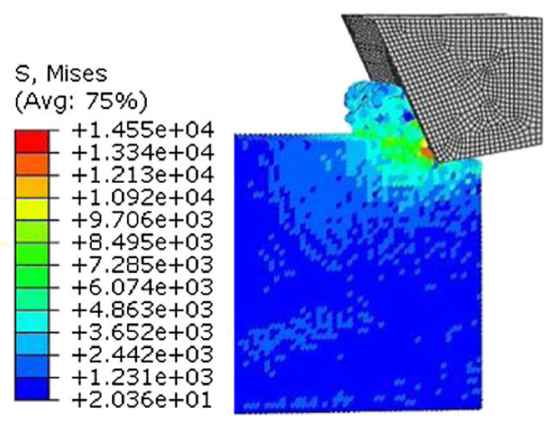

S, Mises (Avg: 75\%)
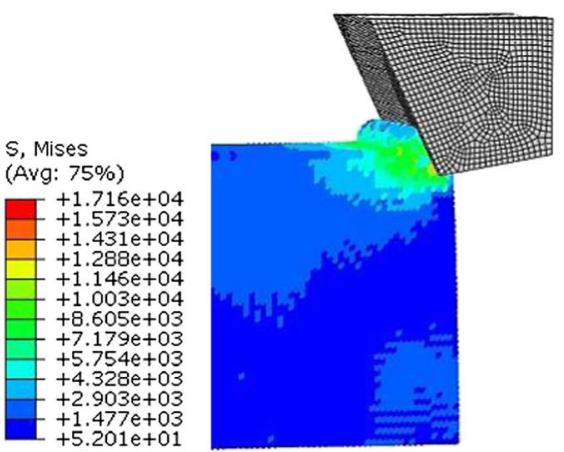

$-25^{\circ}$ rake $(3 \mu \mathrm{s})$

$-25^{\circ}$ rake $(1.5 \mu \mathrm{s})$

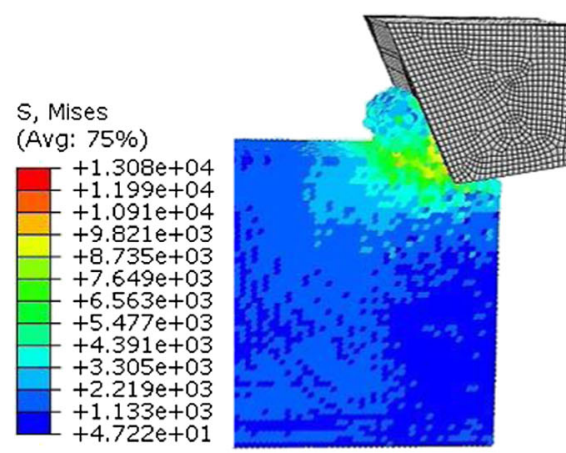

5, Mises (Avg: 75\%)
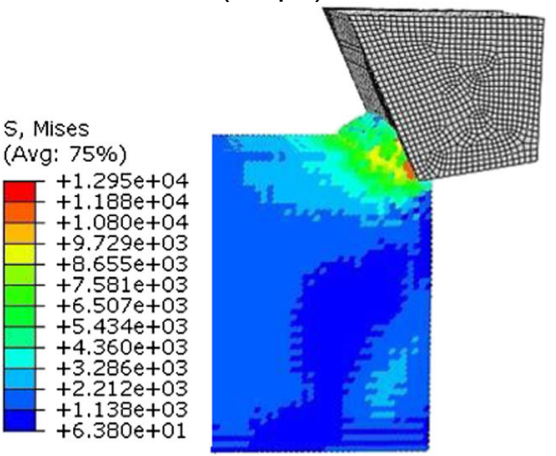

$-30^{\circ}$ rake $(3 \mu \mathrm{s})$

$-30^{\circ}$ rake $(1.5 \mu \mathrm{s})$

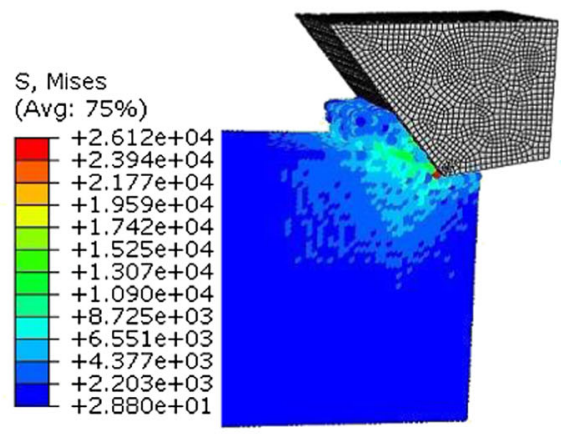

$-40^{\circ}$ rake $(3 \mu \mathrm{s})$

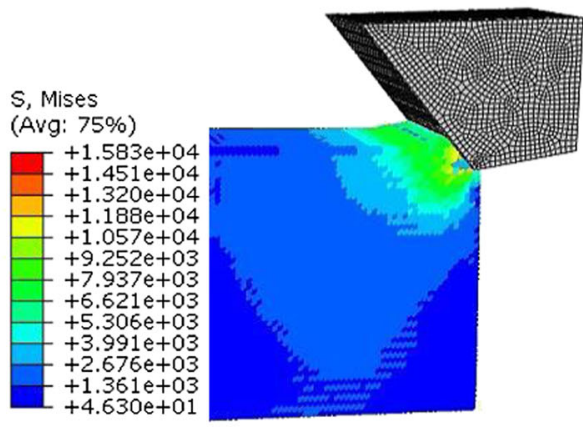

$-40^{\circ}$ rake $(1.5 \mu \mathrm{s})$

Fig. 12 Von-Mises stresses (MPa) and chip formation for different rake angle tool from initial to steady-state 
Fig. 13 SEM images of silicon chips for different rake angle tools

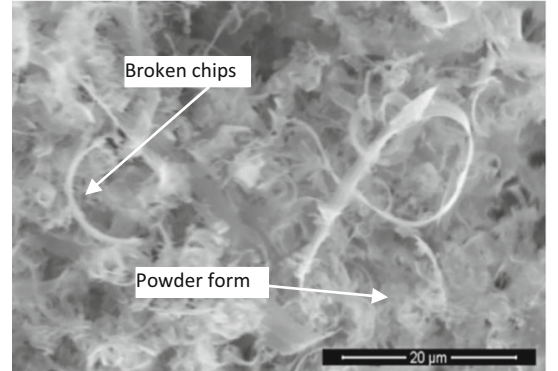

$-25^{\circ}$ rake tool

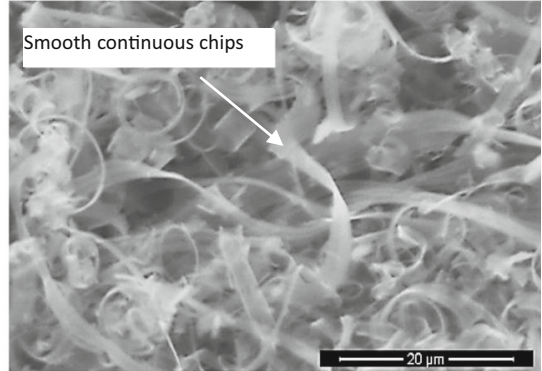

$-30^{\circ}$ rake tool

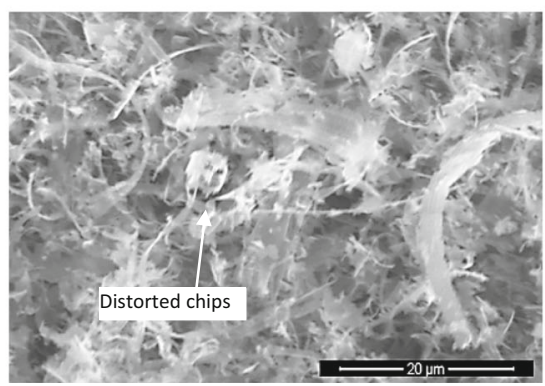

$-40^{\circ}$ rake tool

Tool wear in SPDT of silicon has previously been attributed to the formation of $\mathrm{SiC}$ and diamond-like carbon particles [12], or dynamic hard particles [35] scratching or ploughing on the tool flank face forming groove wear. The chemical reaction of diamond carbon and silicon at a high cutting temperature of $959 \mathrm{~K}$ [34] in the presence of oxygen may lead to the formation of silicon carbide. The formation of SiC due to the silicon-carbon reaction is a significant factor to investigate as it affects material removal mechanism and tool wear. Energy-dispersive X-ray spectroscopy (EDX) analysis was performed on all the chips collected during all facing cuts using three different rake angle tools. Chips collected during both ductile machining and brittle machining were analysed for the presence of $\mathrm{SiC}$. No trace of $\mathrm{SiC}$ formation was detected in all the chips analysed during EDX analysis. Figure 14 presents the EDX spectrum of the collected silicon chips in the SPDT study. The presence of carbon in the EDX analysis was determined as carbon contamination in the chamber.

\subsection{Tool wear}

Tool wear study was carried out using scanning electron microscopy (SEM), and diamond tools were inspected for any initial damage prior to machining. The results were evaluated
Fig. 14 EDX spectrum of silicon chips obtained in SPDT study

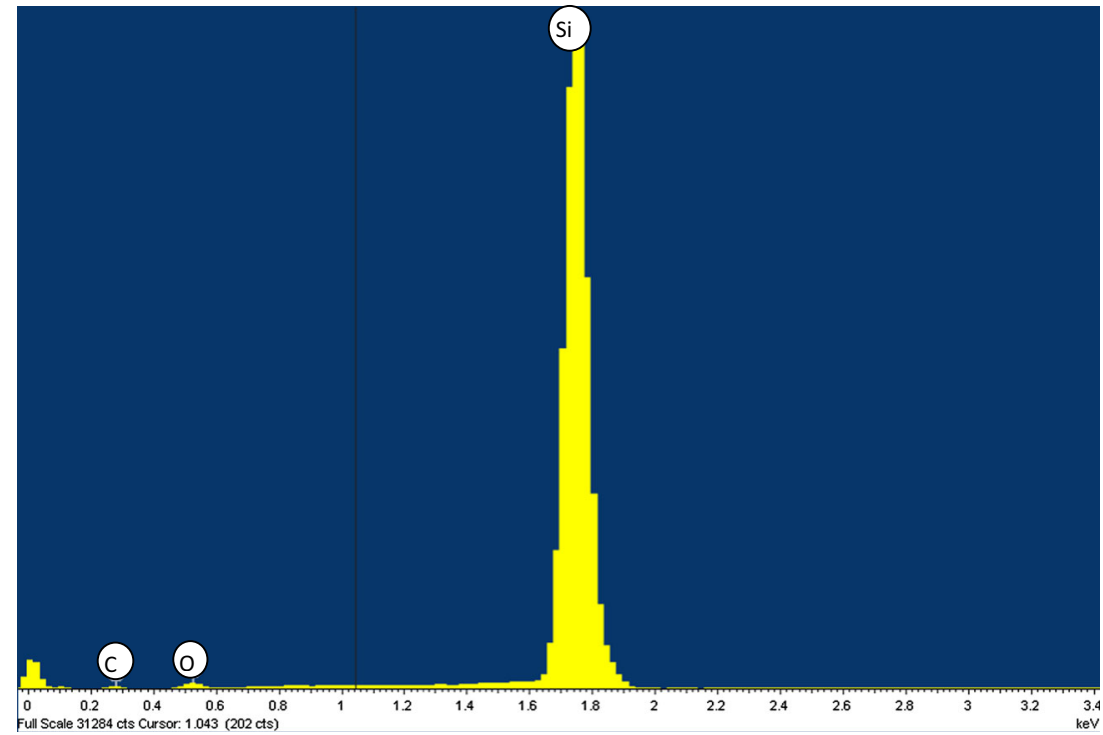


Fig. 15 SEM image of flank and crater wear of $-25^{\circ}$ tool
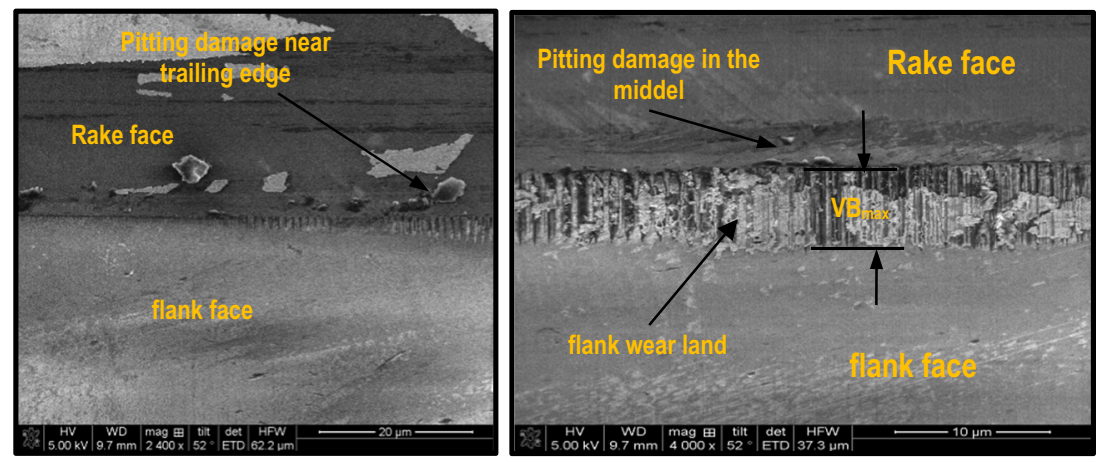

by comparing before and after SEM measurements. Previous studies suggest that abrasive, chemical and thermal wear mechanisms are the possible wear mechanisms in SPDT of silicon $[11,12,36]$. Typically multiple tool wear mechanisms can be active, but only one tool wear mechanism is dominant for a specific workpiece material and for a certain cutting regime. In both the trials of this study, mainly frictional groove wear at flank face was found dominant for all the tools. Tool wear started at the cutting edge shifting the edge towards the rake face and making grooves on the flank side of the tools. This is due to maximum stress intensity and maximum friction found at the cutting edge and the trailing flank surface. For the $-25^{\circ}$ diamond tool, the pitting damage was also observed at the rake face of the tool in both the trials. The pitting damage was found mainly due to chipping phenomenon. For the other two tools, no crater wear was observed in both the trials. Figure 15 shows the SEM images of diamond tool indicating crater wear and flank wear of $-25^{\circ}$ diamond tool.

Figure 16 presents the frictional groove wear contour in all three tools that appeared after machining silicon. Uniform width of flank wear land was found in the middle of cutting edge narrowing down in the form of the curve towards the edges. The flank wear land width for the $-40^{\circ}$ rake tool was recorded $3 \mu \mathrm{m}$ much smaller than 6.5 and $7.5 \mu \mathrm{m}$ for $-30^{\circ}$ and $-25^{\circ}$ rake angle tools, respectively. This is possibly due to the clearance angle of $25^{\circ}$ compared to $10^{\circ}$ for the other two tools.

A crack was found to appear in the wear land area of $-25^{\circ}$ rake angle tool connecting the rake and flank faces of the tool. Although high thermal conductivity of diamond tool and silicon along with coolant significantly contributes to reducing the cutting temperature, with the increased frictional resistance due to wear, cutting temperature may increase significantly. Diamond tools tend to undergo thermal cracking and chemical wear at higher cutting temperatures. The crack that appeared in the wear land of the $-25^{\circ}$ rake tool can possibly be the result of thermal cracking, rapid heating and cooling, or fatigue in achieving the longest cutting distance.

While considering tool wear, a significant factor to consider is gradual tool degradation as a function of cutting distance. Figure 17 shows comparison of the cutting tool wear resistance performance which is characterised as the ratio of tool
Fig. 16 Tool wear pattern for different rake angle tools in trial 1 and trial 2

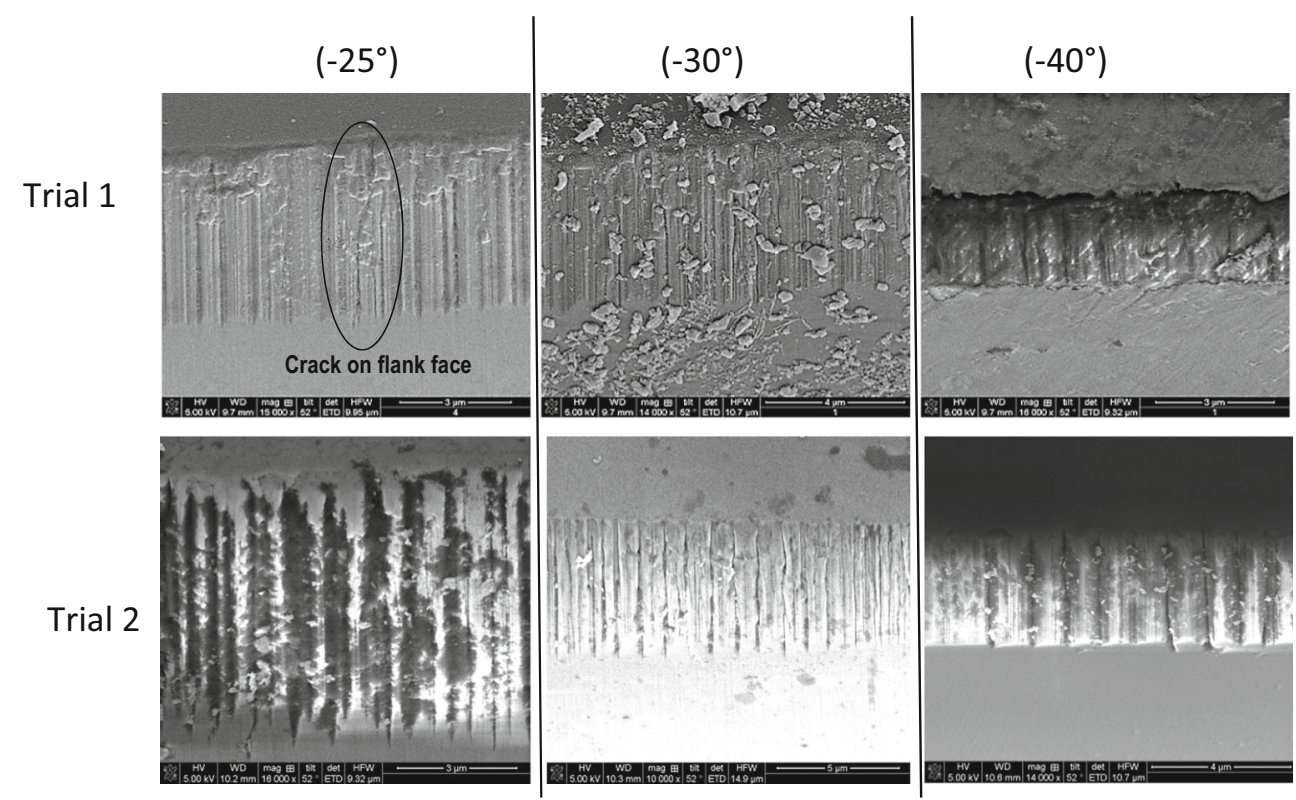




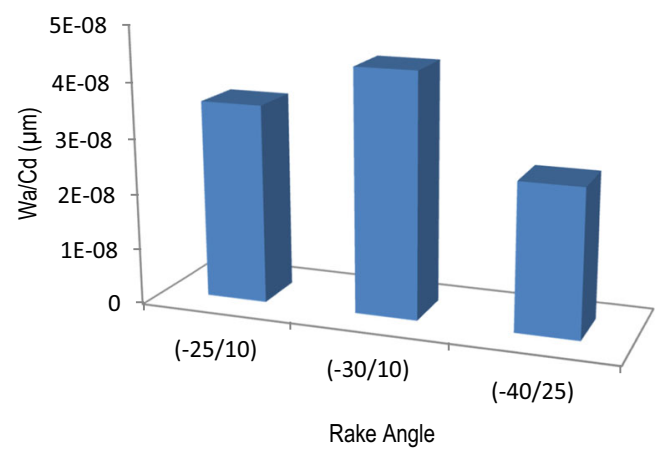

Fig. 17 Comparison of cutting tool wear resistance performance

wear area to cutting distance. Although the least ratio for the $\left(-40^{\circ}\right)$ rake found is in agreement with a previous study [37], which suggests less tool wear for large negative rake tools, the results do not constitute a direct proportionality relationship of decreasing tool wear with increasing negative rake angle. The tool with the $-30^{\circ}$ rake was found to undergo the highest tool wear than $-40^{\circ}$ as a function of cutting distance.

It was also noted that although observing the least frictional wear rate, diamond tool with the $-40^{\circ}$ rake failed to maintain HPPT of silicon for longer cutting distance compared to the $-25^{\circ}$ rake tool. This validates the importance of an optimal negative rake in machining brittle materials, where the worn tool can also machine in ductile regime using proper rake angle tool.

The effect of gradual tool wear can also be evaluated in the form of increased surface roughness of the machined surface. Figure 18 presents the surface roughness variation with respect to cutting distance. With the increasing cutting distance, the tool edge deteriorates and affects the machined surface. It can be noticed from the cutting force plot that major wear for all rake tools transpired before $20 \mathrm{~km}$ of cutting distance and then gradual frictional wear persisted for the remaining cutting distance. It is also interesting to note that at similar tool wear area, the DBT point changes as a function of rake angle. Due to the tool wear, insufficient hydrostatic stress level along with stress disproportionality under the cutting edge result in DBT of the material. Unlike the $-30^{\circ}$ and $-40^{\circ}$ rake tools, the $-25^{\circ}$ rake angle tool was found to generate the required hydrostatic pressure for HPPT of silicon even in worn conditions.

\section{Conclusion}

The effect of tool rake angles was investigated in SPDT of silicon using experimental and simulation methods. The performance of diamond tools was analysed based on cutting forces, chip formation, surface roughness and tool wear studies. The analysis of these studies leads to the following conclusions:

- The mechanism of plastic deformation in SPDT of silicon reliant on pressure-induced continuous material removal using negative rake angle tools. The material removal using positive rake tools procured in the form of cracks rather than continuous chip removal, and final machined surface quality is dependent on crack direction.

- Surface roughness deteriorates with the increase of tool wear. However, ductile mode machining can still be achieved with the worn tool provided the required hydrostatic pressure is maintained for HPPT of silicon during machining and this performance was found highly dependent on rake angles. Diamond tool with $-25^{\circ}$ rake angle maintained the longest ductile mode machining even undergoing higher frictional wear rate than the $-40^{\circ}$ rake tool.

- The effect of rapid or progressive wear of diamond tool on HPPT of silicon varies for different rake angle tools. The tool with $-30^{\circ}$ rake angle was found to undergo the highest frictional resistance while cutting (111) silicon
Fig. 18 Surface roughness trend with respect to cutting distance

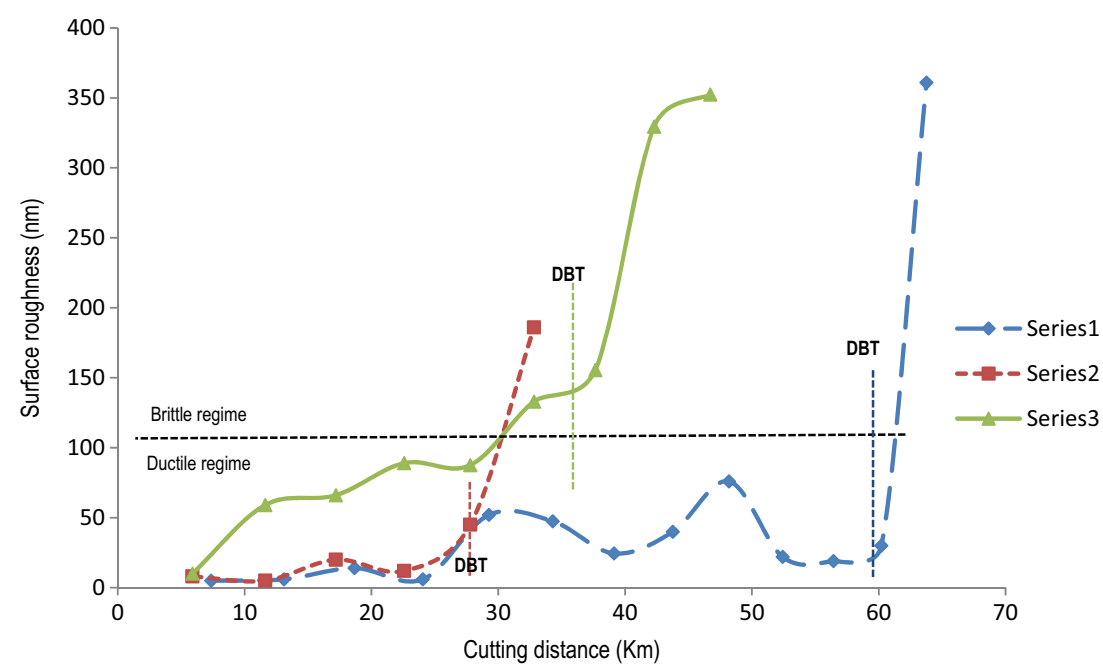


wafer and observed the shortest cutting distance than the other two tools. The relatively high tangential forces in experiments and reduction in shear plane length and lower von Mises stress in SPH simulation corroborate well for this behaviour.

- No direct correlation can be formed for tool performance with increasing or decreasing negative rake angle.

Acknowledgements The authors gratefully acknowledge the financial support from the EPSRC (EP/K018345/1), Strathclyde University Impact Acceleration Account (120526/RA9029) and Royal Society-NSFC international exchange programme (IE141422) for this study.

Open Access This article is distributed under the terms of the Creative Commons Attribution 4.0 International License (http:// creativecommons.org/licenses/by/4.0/), which permits unrestricted use, distribution, and reproduction in any medium, provided you give appropriate credit to the original author(s) and the source, provide a link to the Creative Commons license, and indicate if changes were made.

\section{References}

1. Goel S et al (2015) Diamond machining of silicon: a review of advances in molecular dynamics simulation. Int $\mathrm{J}$ Mach Tools Manuf 88:131-164

2. Kailer A, Gogotsi YG, Nickel KG (1997) Phase transformations of silicon caused by contact loading. J Appl Phys 81(7):3057

3. Zhang L, Zarudi I (2001) Towards a deeper understanding of plastic deformation in mono-crystalline silicon. Int J Mech Sci 43(9): 1985-1996

4. Leung TP, Lee WB, Lu XM (1998) Diamond turning of silicon substrates in ductile-regime. J Mater Process Technol 73(1-3):42-48

5. Blake PN, Scattergood RO (1990) Ductile-regime machining of germanium and silicon. J Am Ceram Soc 73(4):949-957

6. Chao CL, Ma KJ, Liu DS, Bai CY, Shy TL (2002) Ductile behaviour in single point diamond-turning of single-crystal silicon. $\mathrm{J}$ Mater Process Technol 127(2):187-190

7. Yan J, Syoji K, Kuriyagawa T, Suzuki H (2002) Ductile regime turning at large tool feed. J Mater Process Technol 121(2-3):363-372

8. Shibata Tet al (1996) Ductile-regime turning mechanism of singlecrystal silicon. Precis Eng 18(2-3):129-137

9. Fang FZ, Venkatesh VC (1998) Diamond cutting of silicon with nanometric finish. CIRP Ann Manuf Technol 47(1):45-49

10. Uddin MS, Seah KHW, Rahman M, Li XP, Liu K (2007) Performance of single crystal diamond tools in ductile mode cutting of silicon. J Mater Process Technol 185(1-3):24-30

11. Li XP, He T, Rahman M (2005) Tool wear characteristics and their effects on nanoscale ductile mode cutting of silicon wafer. Wear 259(7-12):1207-1214

12. Zong WJ, Sun T, Li D, Cheng K, Liang YC (2008) XPS analysis of the groove wearing marks on flank face of diamond tool in nanometric cutting of silicon wafer. Int J Mach Tools Manuf 48(15):1678-1687

13. Patten JA, Gao W (2001) Extreme negative rake angle technique for single point diamond nano-cutting of silicon. Precis Eng 25(2):165-167

14. Limido J et al (2007) SPH method applied to high speed cutting modelling. Int J Mech Sci 49(7):898-908

15. Zhao H et al (2013) Influences of sequential cuts on micro-cutting process studied by smooth particle hydrodynamic (SPH). Appl Surf Sci 284:366-371
16. Gasiorek D (2013) The application of the smoothed particle hydrodynamics ( $\mathrm{Sph}$ ) method and the experimental verification of cutting of sheet metal bundles using a guillotine. J Theor Appl Mech 51(4): 1053-1065

17. Gingold RA, Monaghan JJ (1977) Smoothed particle hydrodynamics theory and application to non spherical stars. R Astron Soc 181: 375-389

18. Priyadarshinin A, Pal SK, Samantaray AK (2012) Finite element modeling of chip formation in orthogonal machining. In: Davim JP (ed) Statistical and computational techniques in manufacturing. Springer-Verlag, Berlin Heidelberg, 101-144

19. Aspinwall DK, Soo SL (2007) Developments in modelling of metal cutting processes. Proc Inst Mech Eng L J Mater Des Appl 221(4): 197-211

20. Ueda K et al (1991) A J-integral approach to material removal mechanisms in microcutting of ceramics. CIRP Ann Manuf Technol 40(1):61-64

21. Xlet JQBAEZHM (1996) A study on shear banding in chip formation of orthogonal machining. Int $J$ Mach Tools Manuf 36(7):835-847

22. Obikawa $\mathrm{T}$ et al (1997) Application of computational machining method to discontinuous chip formation. J Manuf Sci Eng 119(4B): 667-667

23. Monaghan JJ (2000) SPH without a tensile instability. J Comput Phys 159(2):290-311

24. Villumsen M, T. F. (2008) Simulation of metal cutting using smoothed particle hydrodynamics. LS-DYNA Anwenderforum. Metallumformung III. Bamberg, 17-36

25. Drucker DC, Prager W (1952) Soil mechanics and plastic analysis or limit design. Q Appl Math 10(2):157-165

26. Simulia (2014) Abaqus User documentation. softwar manual. 6.14

27. Durazo-Cardenas I, Shore P, Luo X, Jacklin T, Impey SA, Cox A (2007) 3D characterisation of tool wear whilst diamond turning silicon. Wear 262(3-4):340-349

28. Blackley WS, Scattergood RO (1992) Ductile-regime machining model for diamond turning of brittle materials. Precis Eng 14(2):118

29. Ohta T, Yan J, Yajima S, Takahashi Y, Horikawa N, Kuriyagawa T (2007) High-efficiency machining of single-crystal germanium using large-radius diamond tools. Int J Surf Sci Eng 1(4):374

30. Ohrimenko GM (1988) Single crystal silicon piezoelectric ceramics and ferrite under uniaxial compression. Tranlslated from Problemy Prochonosti 9:45-50

31. Mir A, Luo X, Siddiq A (2017) Smooth particle hydrodynamics study of surface defect machining for diamond turning of silicon. Int J Adv Manuf Technol 88(9-12):2461-2476

32. Cheung CF, S. To, Lee WB (2002) Anisotropy of surface roughness in diamond turning of brittle single crystals. Mater Manuf Process 17(2):251-267

33. Yan J, Zhao H, Kuriyagawa T (2009) Effects of tool edge radius on ductile machining of silicon: an investigation by FEM. Semicond Sci Technol 24(7):075018

34. Goel S, Luo X, Reuben RL (2013) Wear mechanism of diamond tools against single crystal silicon in single point diamond turning process. Tribol Int 57:272-281

35. Cai MB, Li XP, Rahman M (2007) Characteristics of "dynamic hard particles" in nanoscale ductile mode cutting of monocrystalline silicon with diamond tools in relation to tool groove wear. Wear 263(7-12):1459-1466

36. Yan J, Syoji K, Tamaki JI (2003) Some observations on the wear of diamond tools in ultra-precision cutting of single-crystal silicon. Wear 255(7-12):1380-1387

37. Born DK, Goodman WA (2001) An empirical survey on the influence of machining parameters on tool wear in diamond turning of large single-crystal silicon optics. Precis Eng 25(4):247-257 